\title{
Effect of Drying Methods and Extraction Time-Temperature Regime on Mango Kernel Lipids
}

\author{
Jhumur Banerjee ${ }^{1}$, Antonio F. Patti ${ }^{2}$, Douglas MacFarlane ${ }^{2}$, R. Vijayaraghavan ${ }^{2}$, Ramkrishna Singh ${ }^{1}$, \\ Amit Arora ${ }^{1,3^{*}}$
}

${ }^{1}$ IITB-Monash Research Academy, IIT Bombay, Mumbai, Maharashtra, India, 400076

${ }^{2}$ School of Chemistry, Faculty of Science, Monash University, Clayton campus, VIC, Australia

${ }^{3}$ Indian Institute of Technology, Powai, Maharashtra, India

*Corresponding author: Amit Arora, Indian Institute of Technology, Powai, Maharashtra, India, Tel: +91(22)-2576-7293;

E-mail: aarora@iitb.ac.in

\begin{abstract}
In this study, effect of drying method and time temperature regime of extraction on quality of mango kernel lipid was evaluated. Hot air drying required drying of seeds for long intervals and exposure to higher temperature, where as microwave drying was found to be quick due to heating induced at the molecular level. The drying time under optimized conditions for microwave was reduced by 34 folds when compared with hot air drying. Parameters including drying temperature, extraction time, lipid yield and fatty acid profile were evaluated. The study shows that modification of extraction method for lower temperature and lesser time does not alter the quality and quantity of lipids from mango kernel (10.8\%). Structural changes induced due to drying were studied using scanning electron microscopy. Statistical analysis showed that drying conditions and extraction conditions affected the lipid yield. The further comparison between two methods was done in terms of fatty acid profiles and oxidative stability. The stability of lipid was estimated by measuring the ratio of linoleic acid to palmitic acid for all extraction conditions. The ratio of $\mathrm{C} 18: 2 / \mathrm{C} 16$ was similar for microwave irradiation when compared to hot air dried samples $(1.0$ - 1.2). It was concluded that mild microwave power level (180W) helps in quick drying of kernels. The structure was found to be intact with minimal damage to starch granules. Lower microwave power level helped in retention of the lipid yield and quality while higher microwave power levels significantly affected the unsaturated fatty acids.
\end{abstract}

Received Date: February 13, 2016

Accepted Date: May 11, 2016

Published Date: May 16, 2016

Citation: Arora, A., et al. Effect of Drying Methods and Extraction Time-Temperature Regime on Mango Kernel Lipids. (2016) Int J Food Nutr Sci 3(1): 229-338

DOI: $10.15436 / 2377-0619.16 .048$

Keywords: Mango kernel; Microwave; Fatty acids; Scanning electron microscopy

\section{Introduction}

Worldwide production of mango pulp has reached more than 1.5 million tonnes with an annual production of fruit crossing 43 million tonnes. Asia accounts for nearly $84 \%$ of total pulp production in which India is the largest producer ${ }^{[1]}$. Nearly 18.4 million tonnes of Mango fruits production was recorded in 2014 ${ }^{[2]}$. Industries process the mango fruits for pulp production and generate a huge quantity of waste which varies from 25 - 40\%. Composting and biogas formation is mainly followed in large industries, while in small scale industries; the waste is disposed at a far site. The current disposal mechanism lacks value addition of waste and many important nutrients such as bioactive compounds are lost. The waste also being rich in moisture leads to environmental pollution. Limited land filling area especially in developing countries pose disposal challenges.

As shown in Figure 1, the mango processing waste mainly consists of peels and seeds. Mango peels proximate composition

Copyrights: (C) 2016 Arora, A. This is an Open access article distributed under the terms of Creative Commons Attribution 4.0 International License. 
shows the presence of a significant amount of pectin, phenolics and carotenoids like bioactive ${ }^{[3,4]}$. They play an important role as health-promoting additives in food industry. The spent peel from pectin extraction may also be used for utilisation of cellulose which is around 35\%. Mango kernels are found to be rich in starch (50-60\%), lipids (8 - 14\%) and protein (6 - 10\%). A few reports on characterization of protein showed that it can be a good source for essential amino acids ${ }^{[5]}$. Researchers have also shown great interest in mango kernel lipids due to peculiar fatty acid profile (Saturated fatty acid 48-55\%; unsaturated fatty acid 45 - 52\%).Mango kernel lipids have been used as a valuable substitute for cocoa butter in food items ${ }^{[6]}$. The cocoa butter consists of saturated (60 - $\left.65 \%\right)$ and unsaturated fatty acids (35 - 40\%). The fatty acids from mango kernels were also used as a lipid base in cosmetics e.g. lipsticks and emollients, in preparation of bio surfactants etc. The tendency of kernel lipids to stay partly solid at room temperature makes it useful to be used in food and cosmetic products especially for developing countries. The lipid can also be blended with other oils which require such applications and the ratio can be tuned as per the product desirability.

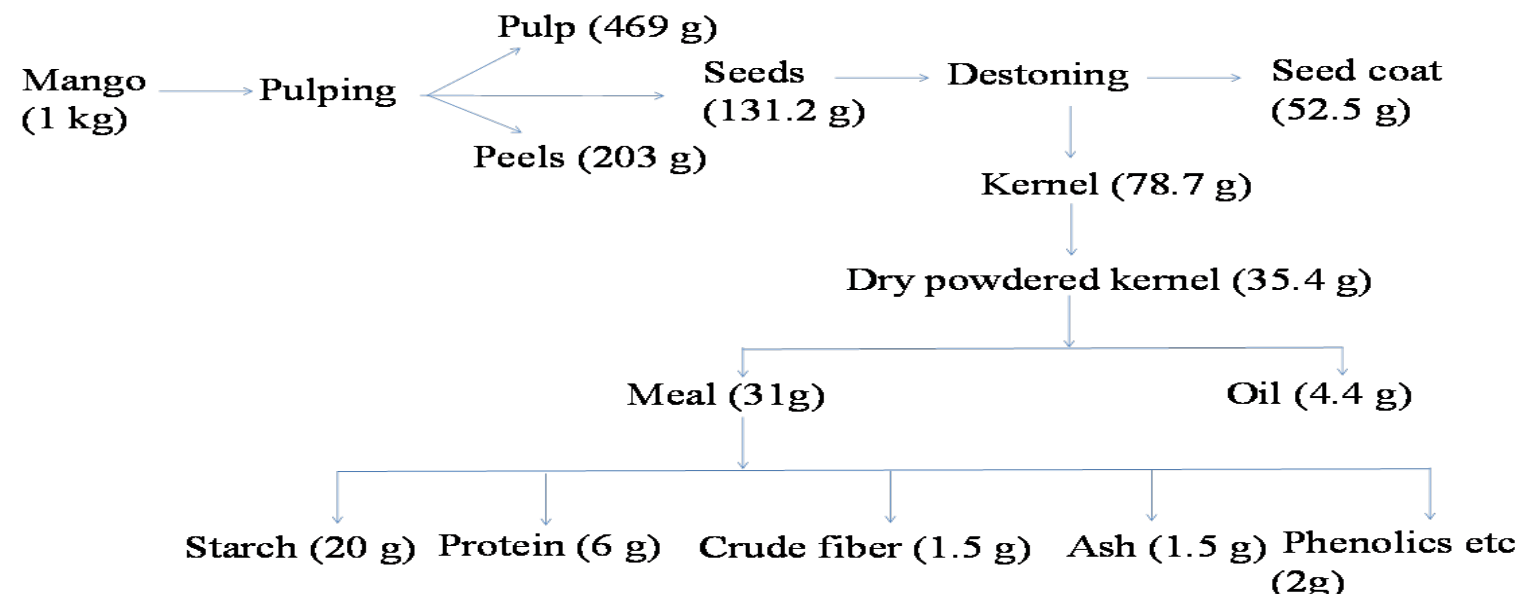

Figure 1: Mass balance for mango processing.

Extraction of lipids from mango kernel is carried out by using various physical, chemical and/or combination of these processes. Cold press or mechanical expeller is a commonly used industrial method where loss of lipids is significant ${ }^{[7,8]}$. Another method for oil extraction is Soxhlet extraction or hot solvent percolation method. The yield obtained in this method is high but it suffers disadvantage of large amount of solvent usage. Hexane is mainly used as solvent which is toxic in nature and reported to be environmentally hazardous. The large solvent usage also incurs high process cost. Also with non polar solvents, drying of material becomes a necessary step before lipids extraction. The yield of mango kernel lipids using hot air drying followed by conventional extraction varies from $7-9 \%$ for Indian varieties ${ }^{[7-9]}$. Other recently developed methods include supercritical fluid extraction using carbon dioxide in which yield was found to vary from 6.5 to $13.5 \%{ }^{[10]}$.

Drying is one of the most important unit operation involved before oil extraction as the yield of the extracted oil is dependent on the moisture content of the material ${ }^{[11]}$. Drying is the most energy intensive operation. Commonly used methods for drying are sun drying, solar drying, hot air drying, vacuum drying, freeze drying or combination of these methods (Sonwai, Kaphueakngam $\&$ Flood 2014). Hot air drying and freeze drying are energy intensive processes ${ }^{[12]}$. The product attributes in case of freeze dried samples are superior as compared to any other drying method. Sun drying requires long intervals of sunlight exposure. The limitations associated with sun drying are inconsistent availability of sunlight, long hours, weather conditions and damage to samples due to environmental fluctuations. Freeze drying is an energy intensive non-disruptive technique but is not widely applicable due to higher cost. Hot air drying is commonly followed in food processing industries owing to its simplicity, development over years and precise control of parameters as compared to above two techniques. The temperature can be varied over a large range and thus, qualitative parameters can be well studied under controlled conditions.

Microwave drying is a novel technique which accelerates the removal of moisture due to vibration of water molecules and volumetric heating. The technique was reviewed for its energy efficiency and quicker drying as compared to other methods ${ }^{[13-15]}$. Microwaves have been used for drying of fruits and vegetables like carrot, spinach leaves and mushroom. The quality attributes were found to be acceptable to that of commercial products ${ }^{[16,17]}$. Previous studies concerning extraction of mango kernel oil have focussed on application of hot air drying on yield of oil, phenolic and antioxidant capacity ${ }^{[18]}$. However, effect of drying methods on structural morphology in relation to oil extraction has not been reported. Also, it would be important to understand how various extraction time-temperatures combinations for a given drying condition bring changes in the oil extractability and oil quality. A quick and effective drying method prior to mango kernel lipid extraction is thus, needed to design a sustainable extraction process. The extraction method modification may add fresh insight into mango kernel lipid extraction which may further be used as an essential oil for various applications.

The present study aims to (i) evaluate and compare the effect of hot air drying and microwave drying on structural morphology of mango kernel powder and (ii) assess the effect of different extraction temperature-time combinations on lipid yields 


\section{Materials and Methods}

\section{Raw material}

The mangoes (Totapuri variety) were obtained from local market. Pulp was removed manually and seed coats were washed with distilled water to remove residual sugars and dried. Seed coats were separated from kernel using a cutter designed specifically for this purpose. The kernels were ground and dried at $105 \pm 2{ }^{\circ} \mathrm{C}$ for proximate analysis ${ }^{[19]}$. Dried powder was sieved $(\leq 500 \mu)$, packed in air tight containers and stored at $4^{\circ} \mathrm{C}$. All reagents were of analytical grade and procured from Merck, India.

\section{Proximate analysis of kernels}

The moisture, ash, lipid, protein and carbohydrate were determined as per standard AOAC methods ${ }^{[19]}$. Sugars were determined using phenolic-sulphuric acid method. Starch was quantified using starch assay kit from Megazyme ${ }^{[20]}$.

\section{Hot air drying of kernel powder}

The initial moisture content of the ground kernel was measured. For drying, a known weight of ground kernels were kept in petri plates in a thin layer and dried at different temperatures. Each reading was measured in triplicate. Hot air drying at $1.0 \mathrm{~m} / \mathrm{s}$ air velocity was done for a temperature range of $40^{\circ} \mathrm{C}, 60^{\circ} \mathrm{C}, 80^{\circ} \mathrm{C}$ and $105^{\circ} \mathrm{C}$ for different time intervals. The moisture content was determined using moisture analyser (Citizen MB 200, India).

For microwave drying, mango kernel powder was kept in petri plates arranged at equal distances in the microwave tray (Model LG MG607APR, output $900 \mathrm{~W})$. Kernels were exposed to four power levels, i.e. 20\% (180 W), $40 \%$ (360 W), $60 \%$ (540 $\mathrm{W})$ and $80 \%(720 \mathrm{~W})$ till constant weight was achieved. Microwave was set up to stay ON for a minute and turn OFF for 30 sec and cycle continued in this fashion until experiments were completed. Thirty seconds OFF time was maintained after every minute to avoid sample burning due to overheating.

\section{Structural and morphological study}

Scanning electron microscopy was conducted on control and treated samples (FEI Quanta 200, Oregon, USA). To prepare the sample, dried powders were adhered to a double sided adhesive tape. Platinum coating at $20 \mathrm{kV}$ was done for $300 \mathrm{~s}$ prior to visualisation of images. The micrographs were studied for presence of granules and structural disruption during drying.

\section{Lipid extraction}

Lipid extraction was carried out using Soxhlet extraction method(Dhara, Bhattacharya \& Ghosh 2010). Ten grams of dried kernel powder was placed in a thimble and hexane was used as an extraction solvent. To prevent the lipid from degradation, $40^{\circ} \mathrm{C}$ and $60^{\circ} \mathrm{C}$ was used as extraction temperature for a time interval of $2 \mathrm{hrs}$ and $4 \mathrm{hrs}$. No significant difference in yield was found for longer extraction periods $(8$ - 24hrs) during initial experiments, thus, temperature and time duration was kept low to avoid degradation of fatty acids. After solvent removal, the lipid was kept at $40^{\circ} \mathrm{C}$ for 24 hours to remove traces of hexane. The obtained lipid was then stored at $4^{\circ} \mathrm{C}$ in amber coloured container until further usage. The yield was calculated on dry basis.

\section{Fatty acid profile and qualitative tests}

The fatty acid profile was determined to compare any changes in fatty acid composition due to different drying methods. The fatty acid composition was determined using gas chromatography equipped with a flame ionization detector (Perkin Elmer, Auto system XL). For flame ionization detector, column used was PE-FFAP, carrier gas nitrogen, Injection temperature and detector temperature was kept at $250^{\circ} \mathrm{C}$. The qualitative parameters such as peroxide value (PV), iodine value (IV), saponification value (SV) and acid value (AV) were determined as per the standard protocols of FSSAI (FSSAI 2012).

\section{Statistical analysis}

The difference between various set of results was tested using one way ANOVA with Dunnett's post-test (Minitab; version 16). The results were expressed as mean \pm standard error. The significance of data was represented in terms of $p$ value ( $p<0.05$ was considered as significant). All tests were performed in triplicates.

\section{Results and Discussion}

\section{Proximate analysis}

The proximate analysis Table 1 showed that mango kernel is richly constituted of carbohydrates ( $58 \pm 2 \%$ starches $)$ with an initial moisture content of $54.5 \pm 3.0 \%$. The protein content was found to be $7.5 \%$. The average lipid content was found to be $12.4 \%$. 
Table 1: Proximate analysis of Totapuri mango kernels

\begin{tabular}{|l|l|}
\hline CONSTITUENTS & QUANTITY \\
\hline Energy & 411.3 K.cal \\
\hline Moisture & $7.8 \pm 1 \%$ \\
\hline Fat & $11.5 \pm 1.4 \%$ \\
\hline Protein & $7 \pm 0.3 \%$ \\
\hline Total Sugars & $15.6 \pm 2.0 \%$ \\
\hline Starch & $54 \pm 0.6 \%$ \\
\hline Ash & $2.1 \pm 0.2 \%$ \\
\hline
\end{tabular}

\section{Drying curves}

The moisture content (w.b) as a function of time for conventional drying and microwave drying are shown in Figure 2 and Figure 3. Conventional method of drying took significantly longer time than microwave. Microwaves reduced the drying time to 14 minutes when used at power level of $180 \mathrm{~W}$ while at $540 \mathrm{~W}$, an exposure of 11 minutes reduced the moisture content to $7.5 \%$. Charring of samples was observed beyond $540 \mathrm{~W}$. For hot air drying, it was noted that drying is continuous with time and lag time was not observed when compared with microwave drying curves. This may be due to vibration of water molecules in case of microwave exposure and surface moisture removal after diffusion of moisture from core of the structure to outer layers due to hydrogen bond breaking. However, lag time in microwave drying process was small and may not have a practical significance.

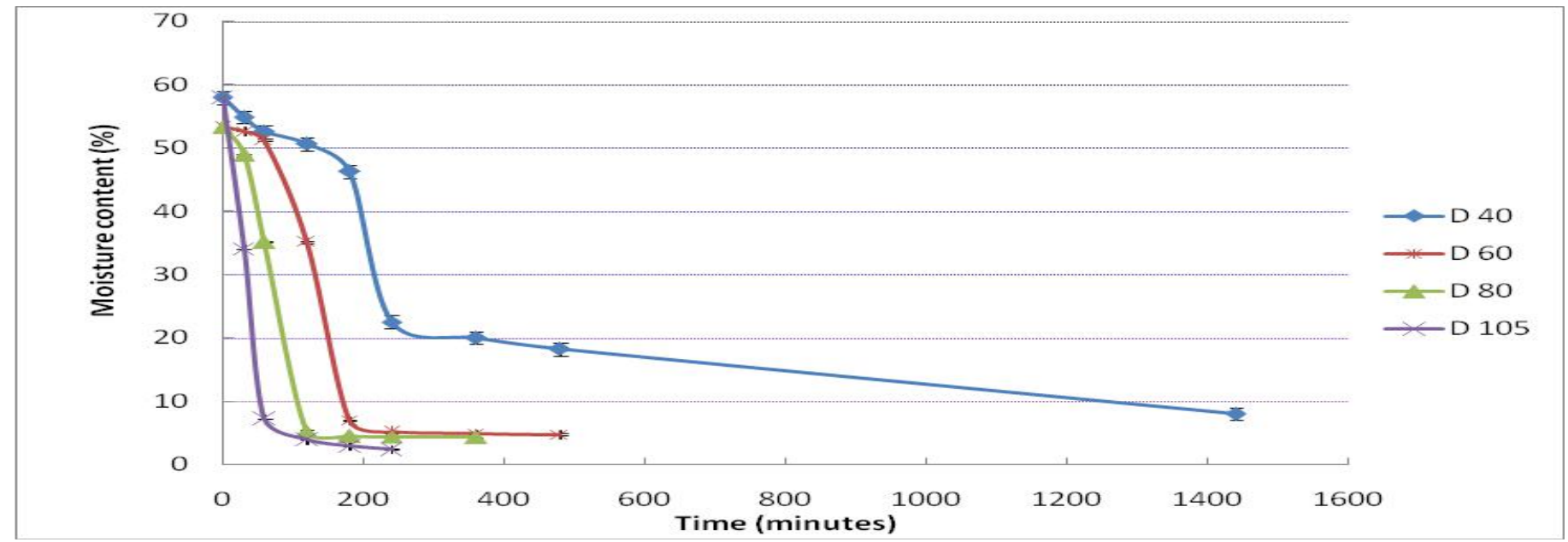

Figure 2: Conventional hot air drying of mango kernels (D denotes drying temperature in ${ }^{\circ} \mathrm{C}$ )

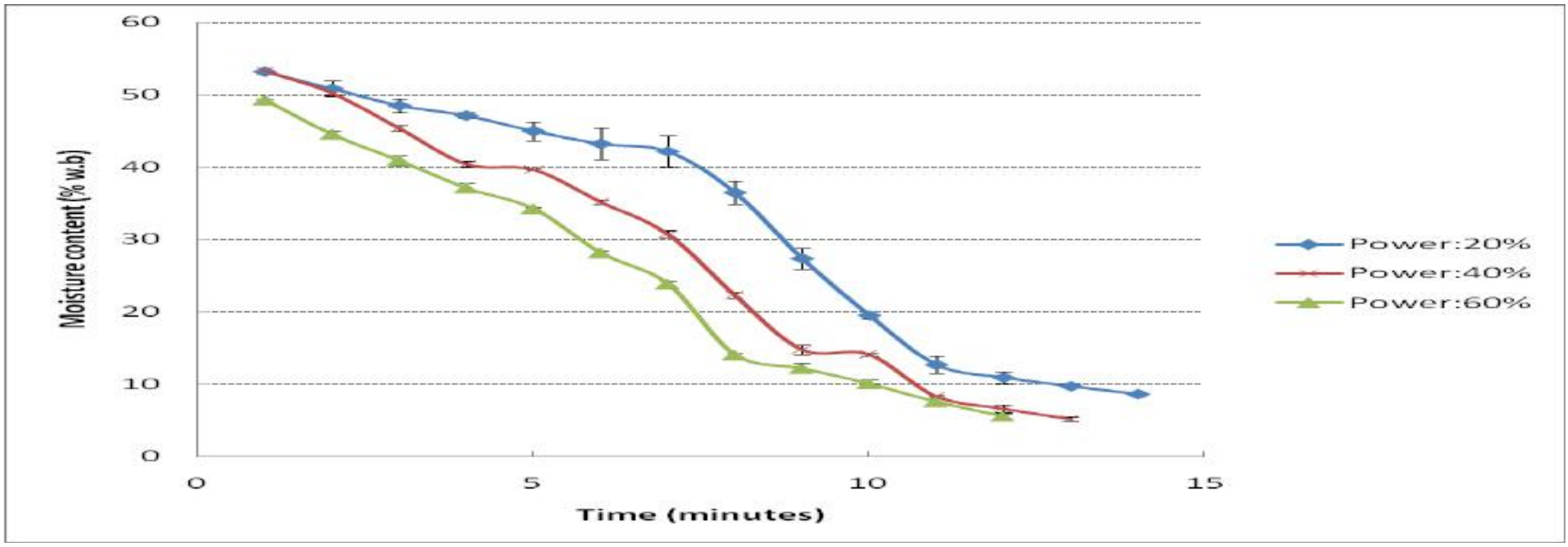

Figure 3: Microwave drying of kernels for drying (20\% power: $180 \mathrm{~W}, 40 \%$ power: $360 \mathrm{~W}, 60 \%$ power: $540 \mathrm{~W})$

\section{Scanning electron microscopy}

Over all structure of mango kernel powder as shown in Figure 4. Indicated presence of oval and circular starch granules. The granules were found to be present inside layered complexes which may be consisting of protein, lipids and structural carbohydrates. Similar findings were reported earlier for wheat $\operatorname{starch}^{[21]}$. Increase in drying temperature was found to affect the oval granules which may be due to disruption of starch granules above their gelatinization temperature, which was found to start at 
$73.4^{\circ} \mathrm{C}$ as reported previously (Kittiphoom 2012). In both the drying methods the layers started to disappear from the surface of starch granules as drying temperature and microwave power level was increased. Structural disruption was clearly visible under hot air drying condition at $105^{\circ} \mathrm{C}$. Mild microwave drying conditions were found to affect the granules to a lesser extent as compared to highest microwave power level in which a rubbery mass may be seen along with no intact granules. The structural change may be due to swelling of starch granules in the presence of significant moisture. Similar results were obtained in studies performed on cooked pasta in previous reports where it was concluded that post cooking the protein and starch layers are not distinguishable and amylose leaches out from the starch granules forming layers ${ }^{[21]}$. Thus, the images were found to be a good evidence of structural changes due to drying.

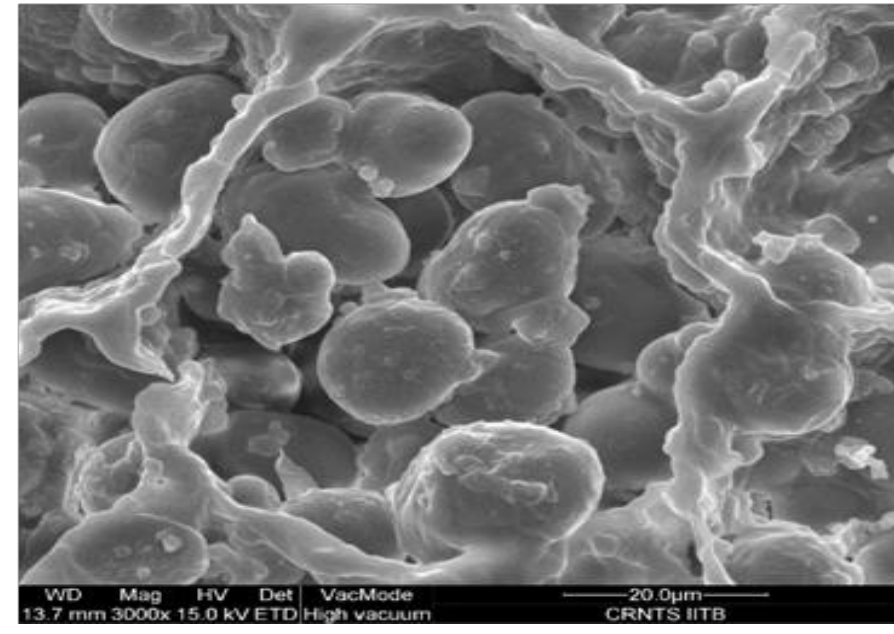

Figure 4 (a): Air dried samples of mango kernel powder

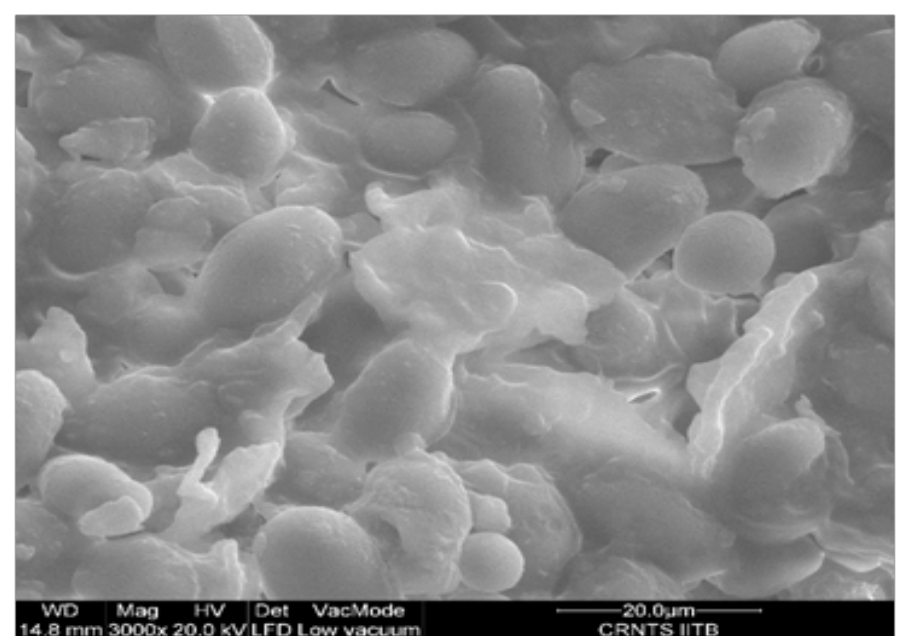

Figure 4 (c): Mango kernels hot air dried at $60^{\circ} \mathrm{C}$

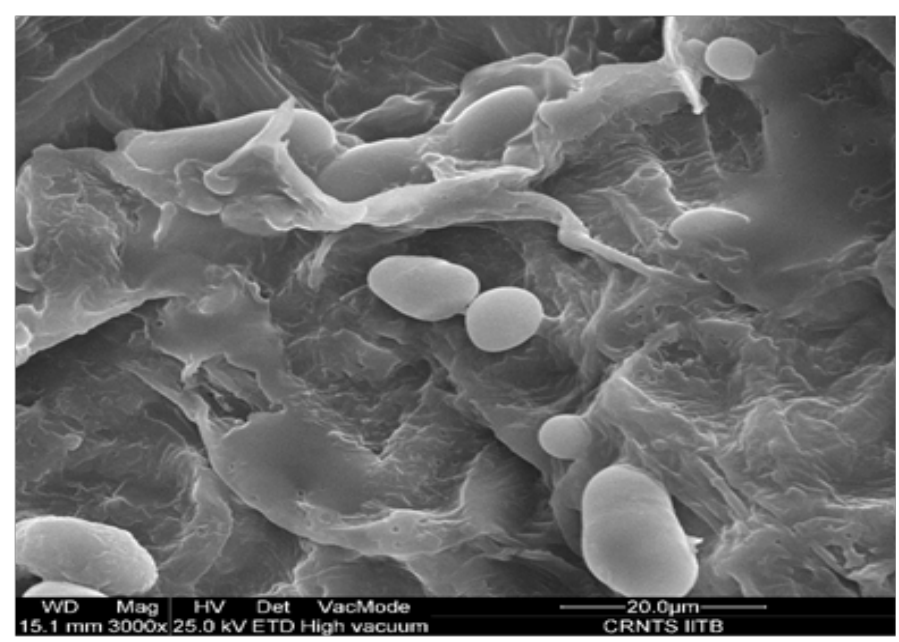

Figure 4 (e): Mango kernels hot air dried at $105^{\circ} \mathrm{C}$

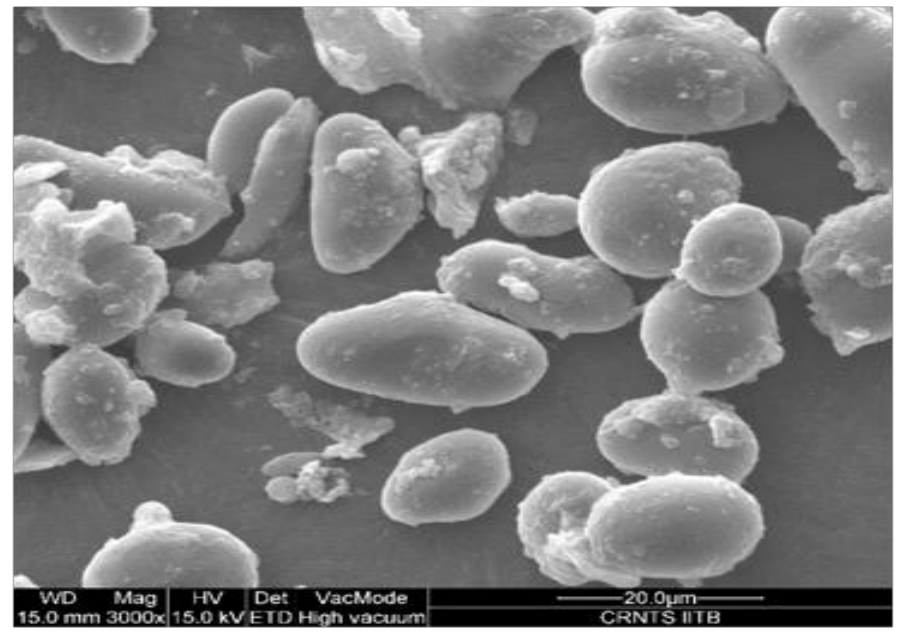

Figure 4 (b): Mango kernels hot air dried at $40{ }^{\circ} \mathrm{C}$

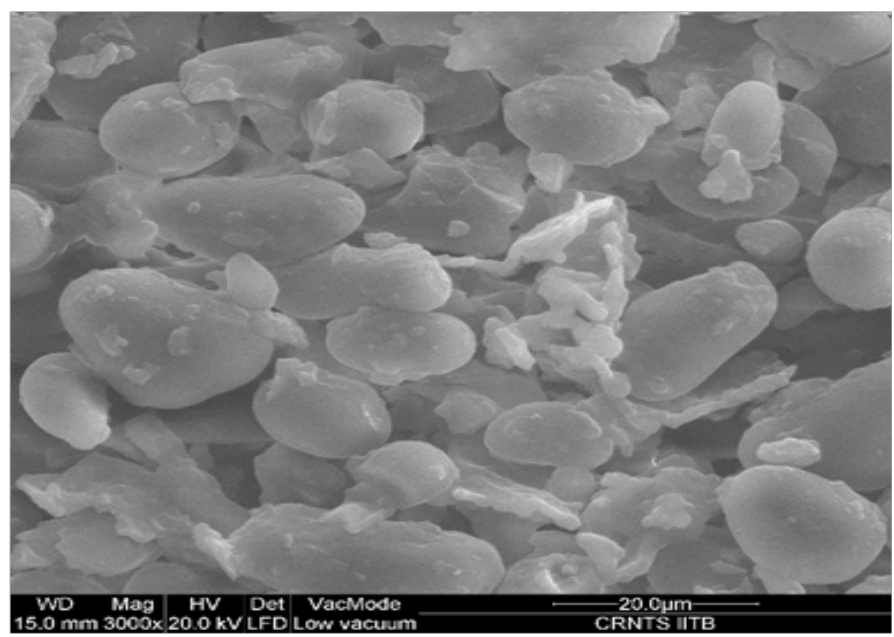

Figure 4 (d): Mango kernels hot air dried at $80^{\circ} \mathrm{C}$

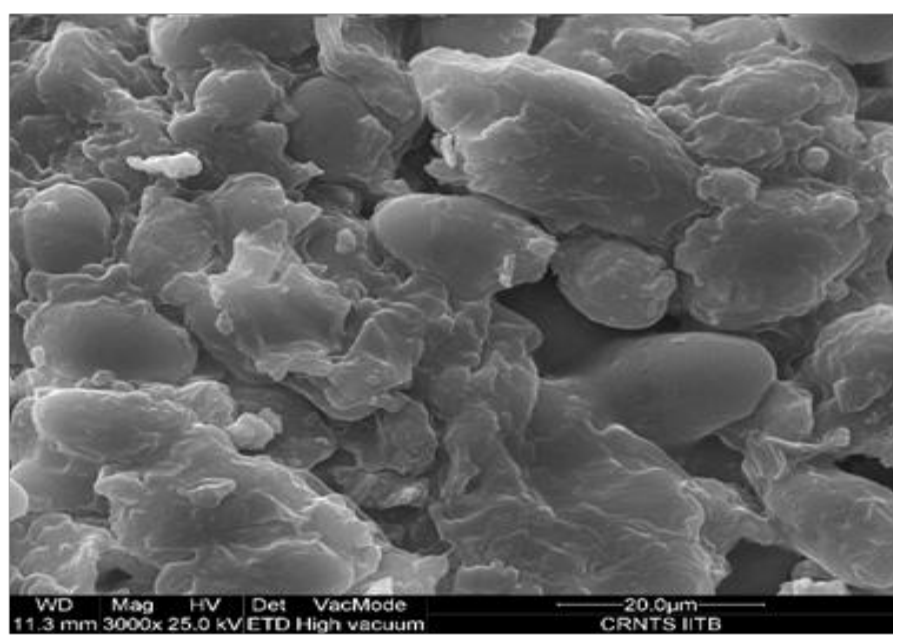

Figure 4 (f): Microwave dried kernels (at $180 \mathrm{~W}$ power level) 


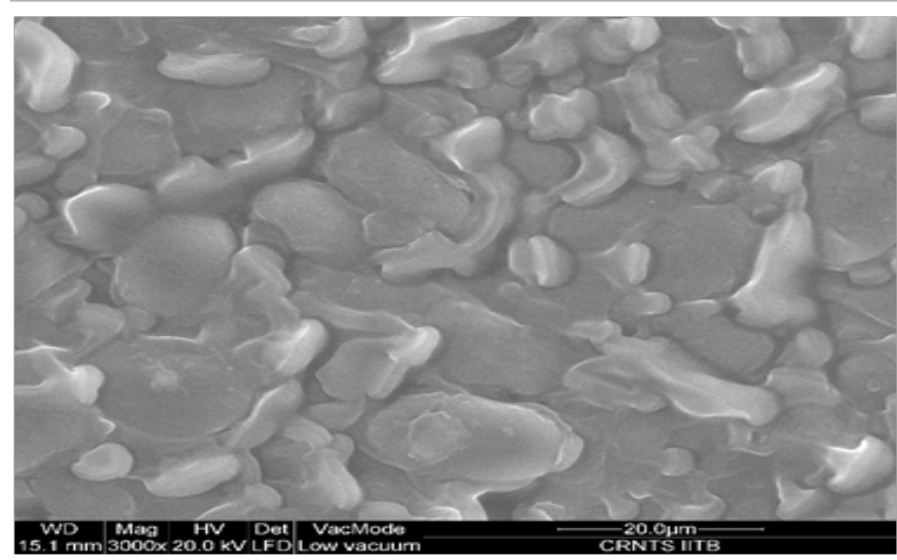

Figure 4 (g): Microwave dried kernels (at $360 \mathrm{~W}$ power level)

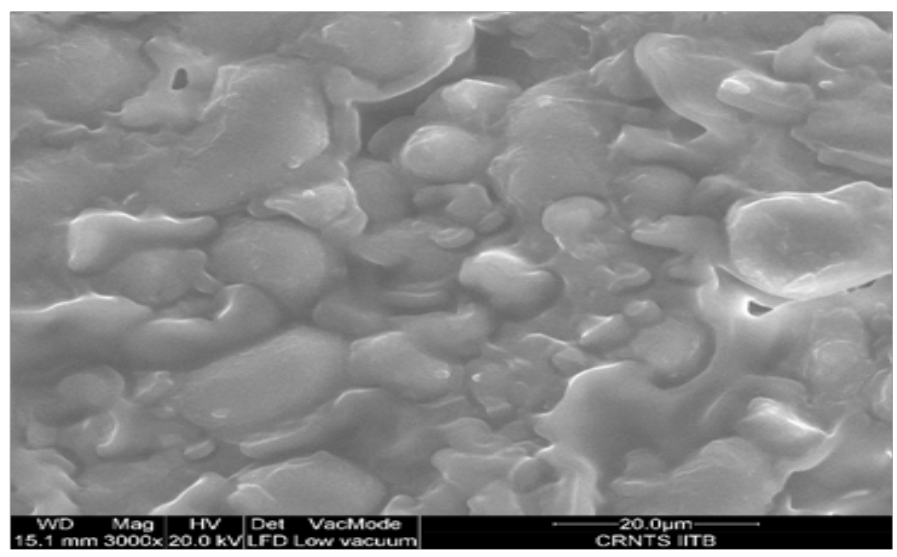

Figure 4 (h): Microwave dried kernels (at $540 \mathrm{~W}$ power level)

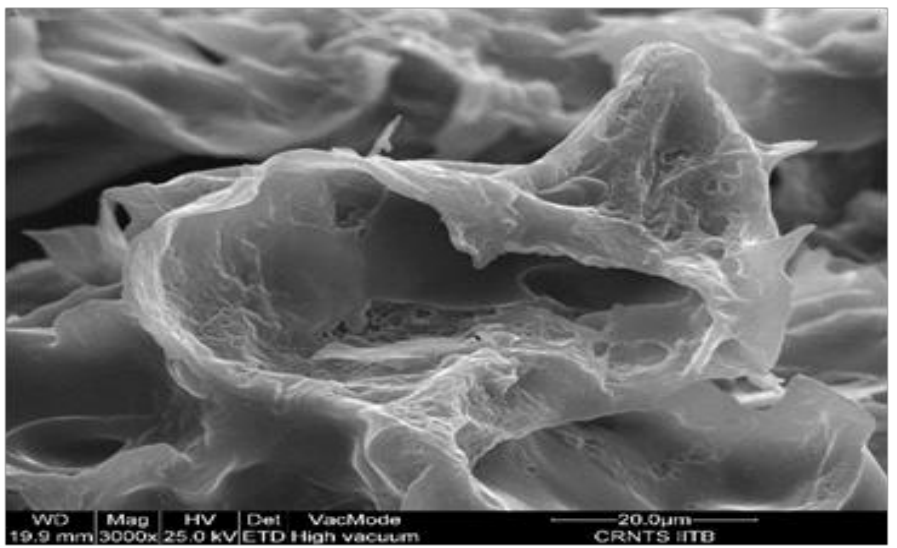

Figure 4 (i): Microwave dried kernels (at $720 \mathrm{~W}$ power level)

\section{Lipid yield}

The yield of lipids from conventional drying at different temperatures was ranging from $8.6-11.5 \%$, while for microwave it was found to be $9.9-11.7 \%$ (Figure 5). The best extraction conditions out of each set (for a given drying method under different extraction conditions) were compared among rows and columns (Table 2). For a given extraction condition, the difference among yields were compared at different drying condition (Hot air $\left(40^{\circ} \mathrm{C}, 60^{\circ} \mathrm{C}, 80^{\circ} \mathrm{C}, 105^{\circ} \mathrm{C}\right)$, and microwave $(180 \mathrm{~W}$ and $360 \mathrm{~W})$ The highest yield was greater than $11 \%$ which was obtained in most of the drying and extraction conditions. It can be concluded that drying at higher temperatures did not affect the lipid yield. Since the time required for microwave drying is significantly less than hot air drying, the same can be used for the drying mango kernels. Extraction yield $\left(40^{\circ} \mathrm{C}, 2 \mathrm{~h}\right)$ from the mango kernel flour, which was dried at $40^{\circ} \mathrm{C}$, was significantly lower than other extraction conditions $(\mathrm{p}<0.05)$. It shows that relatively low temperature and shorter time poses mass transfer limitation problems during oil extraction. At higher temperatures, one would expect high diffusion coefficient of the oil. Micella viscosity would also improve at higher temperatures when exposed for longer time which is apparent (Table 2). In general, solvent extraction is carried out at temperatures as close as possible to the boiling point of solvent which in turn improves the miscibility of oil-solvent system. For example, solvent extraction process with n-hexane solvent (boiling point is $68^{\circ} \mathrm{C}$ ) is typically kept at $60-70^{\circ} \mathrm{C}$. It is noteworthy that by increasing the time of interaction of solvent (from $2 \mathrm{~h}$ to $4 \mathrm{~h}$ ) with the micella helped in extracting oil even at low temperature $\left(40^{\circ} \mathrm{C}\right)$ (Figure 5)

Table 2: Comparison of dryingand extraction conditions on lipid yield

\begin{tabular}{|l|l|l|l|l|l|l|l|}
\hline Extraction & \multicolumn{1}{|c|}{ D1 } & \multicolumn{1}{c|}{ D2 } & \multicolumn{1}{c|}{ D3 } & \multicolumn{1}{c|}{ D4 } & \multicolumn{1}{c|}{ D5 } & \multicolumn{1}{c|}{ D6 } & \multicolumn{1}{c|}{ D7 } \\
\hline $\mathbf{2 h r} / \mathbf{4 0}^{\circ} \mathbf{C}$ & $8.6 \pm 0.5^{\mathrm{b}, 2}$ & $10.9 \pm 0.2^{\mathrm{a}, 1}$ & $9.2 \pm 0.4^{\mathrm{c}, 2}$ & $10.6 \pm 0.3^{\mathrm{a}, 1}$ & $10.3 \pm 0.7^{\mathrm{a}, 1}$ & $11.0 \pm 0.2^{\mathrm{a}, 1}$ & $10.9 \pm 0.2^{\mathrm{b}, 1}$ \\
\hline $\mathbf{4 h r} / \mathbf{4 0}^{\circ} \mathbf{C}$ & $11.3 \pm 1.2^{\mathrm{a}, 1}$ & $11.5 \pm 0.2^{\mathrm{a}, 1}$ & $11.1 \pm 0.2^{\mathrm{b}, 1}$ & $10.5 \pm 0.4^{\mathrm{a}, 1}$ & $10.9 \pm 0.3^{\mathrm{a}, 1}$ & $10.7 \pm 0.3^{\mathrm{ab}, 1}$ & $9.9 \pm 0.2^{\mathrm{c}, 1}$ \\
\hline $\mathbf{2 h r} / \mathbf{6 0}^{\circ} \mathbf{C}$ & $11.5 \pm 0.6^{\mathrm{a}, 1}$ & $10.7 \pm 0.5^{\mathrm{a}, 12}$ & $11.3 \pm 0.4^{\mathrm{a}, 1}$ & $9.8 \pm 0.4^{\mathrm{a}, 2}$ & $10.8 \pm 0.07^{\mathrm{a}, 12}$ & $9.8 \pm 0.3^{\mathrm{b}, 2}$ & $10.6 \pm 0.2^{\mathrm{b}, 12}$ \\
\hline $\mathbf{4 h r} / \mathbf{6 0}^{\circ} \mathbf{C}$ & $11.2 \pm 0.5^{\mathrm{a}, 12}$ & $11.7 \pm 1.1^{\mathrm{a}, 123}$ & $11.2 \pm 0.3^{\mathrm{a}, 12}$ & $10.4 \pm 1.0^{\mathrm{a}, 3}$ & $10.5^{2} \pm 0.2^{\mathrm{a}, 123}$ & $10.0 \pm 0.3^{\mathrm{b}, 3}$ & $11.7 \pm 0.2^{\mathrm{a}, 1}$ \\
\hline
\end{tabular}

$\left(D 1: 40^{\circ} \mathrm{C}, \mathrm{D2}: 60^{\circ} \mathrm{C}, \mathrm{D} 3: 80^{\circ} \mathrm{C}, \mathrm{D} 4: 105^{\circ} \mathrm{C}, \mathrm{D} 5: 180 \mathrm{~W}, \mathrm{D} 6: 360 \mathrm{~W}, \mathrm{D} 7: 540 \mathrm{~W}\right.$; The final moisture contents of dried kernels were $8 \%, 4.7 \%, 4.3 \%$, $2.4 \%, 8.6 \%, 5.2 \%, 5.5 \%$ respectively. Comparisons were made using one way ANOVA across columns and rows separately. Means that do not share a common letter are significantly different e.g. letters containing " $a$ " in one column are similar, " $b$ " and " $c$ " denotes dissimilarity with values with " $a$ "; the first alphabet shows comparison across the columns (vertical comparison) i.e drying vs different extraction conditions and second numeric post coma denotes comparison across rows (horizontal comparison) i.efor a given extraction condition comparison of lipids yields were done for different drying methods). 


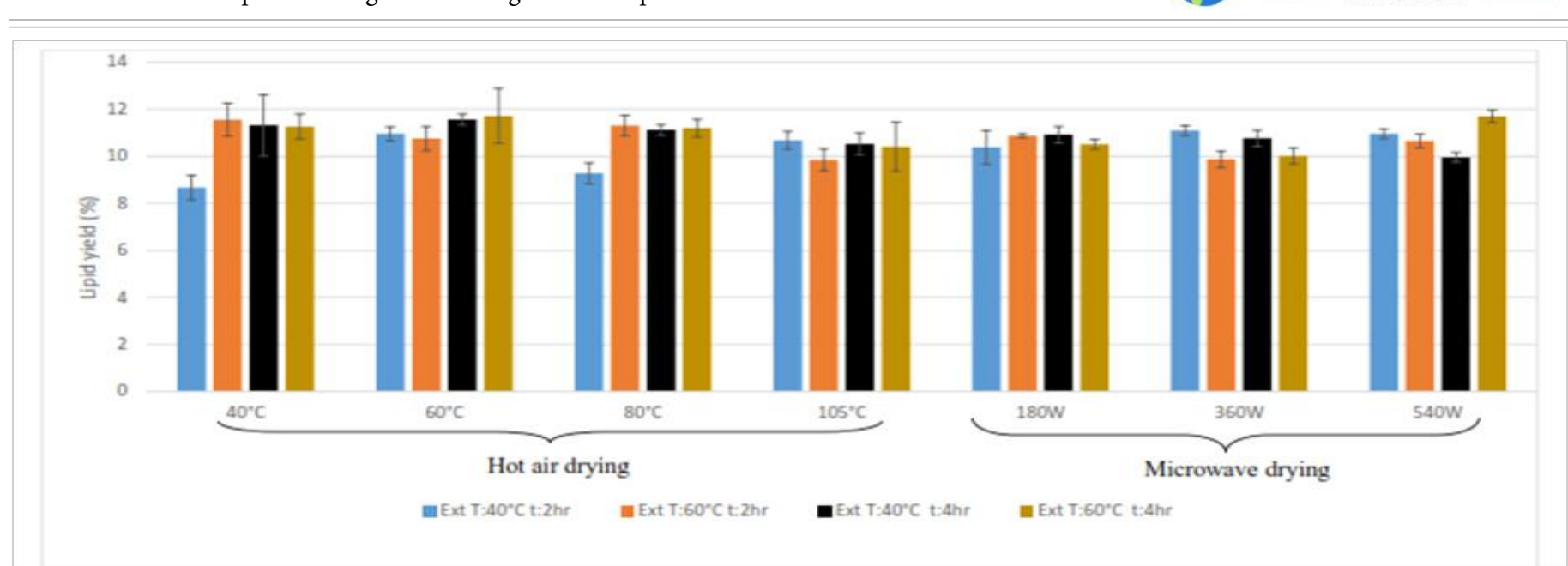

Figure 5: Lipid yield under various drying and extraction conditions

\section{Fatty acid profile and other qualitative parameters}

The fatty acid profile of lipids extracted from conventionally dried seeds and microwave dried kernels were compared and shown in Table 3. Oleic acid and stearic acid were two major fatty acids present in the mango kernel oil. The fatty acid profile in all cases matches well with reference. The quantity of different fatty acids under all hot air drying conditions was found to be consistent, irrespective of extraction conditions. However, an unusual observation was noticed in case of highest microwave power level. The content of oleic acid found to decrease when both drying and extraction conditions were towards higher range. For example, oleic acid content of samples dried at $540 \mathrm{~W}$ and extracted at $60^{\circ} \mathrm{C}$ for $4 \mathrm{~h}$ were found to decrease from $44 \%$ to $41 \%$ for highest microwave power level. The similar observations were found for linoleic acid. To evaluate the effect of the observation mentioned above, oils were extracted posts drying at optimum hot air and microwave drying conditions selected from the Table 3. Oleic acid and linoleic acid as reported in one of the finding ${ }^{[23]}$ were shown to undergo thermal and oxidation reaction to form aldehydes, ketones and alcohols which further undergo oxidation into carboxylic acids when frying of methyl oleate and methyl linoleate as model compounds was done at $180^{\circ} \mathrm{C}$. The results obtained in our study suggests that rapid and localized heating conditions under microwave may have caused degradation of oleic acid while mild microwave power level may be suitable for drying. Also, hot air drying condition did not initiate the deterioration of lipids but prominent effects may be seen on the starch granules at high temperatures. The detailed study on undergoing chemical changes after microwave may further require an understanding of gas chromatography-mass spectra analysis for derivatization and identification of the intermediate compounds.

Table 3: Fatty acid profile for hot air and microwave dried samples

\begin{tabular}{|c|c|c|c|c|c|c|c|}
\hline \multirow{2}{*}{ Fatty acid (\%) } & \multicolumn{7}{|c|}{ Extraction temperature $=40^{\circ} \mathrm{C}$, time $=2$ hours } \\
\hline & D1 & D2 & D3 & D4 & D5 & D6 & D7 \\
\hline Palmitic (C16) & 6.8 & 7.8 & 6.7 & 8.3 & 7.9 & 7.1 & 8.4 \\
\hline Stearic (C18:0) & 36.6 & 38.02 & 36.9 & 35.8 & 37.5 & 38.4 & 36.8 \\
\hline Oleic (C18:1) & 46.9 & 43.7 & 45.1 & 44.7 & 43.1 & 43.5 & 44.0 \\
\hline Linoleic (C18: 2) & 7.3 & 7.8 & 7.9 & 8.5 & 8.9 & 8.8 & 8.5 \\
\hline Linolenic (C18:3) & 0.3 & 0.4 & 0.4 & 0.4 & 0.3 & 0 & 0 \\
\hline Unknown & 1.9 & 2.1 & 2.6 & 2.0 & 1.9 & 2 & 2.0 \\
\hline C18:2/C16 & 1.07 & 1.0 & 1.1 & 1.0 & 1.1 & 1.2 & 1.0 \\
\hline \multirow{2}{*}{ Fatty acid } & \multicolumn{7}{|c|}{ Extraction temperature $=40^{\circ} \mathrm{C}$, time $=4$ hours } \\
\hline & D1 & D2 & D3 & D4 & D5 & D6 & D7 \\
\hline Palmitic (C16) & 7.4 & 7.6 & 7.3 & 8.4 & 7.8 & 7.8 & 8.1 \\
\hline Stearic (C18:0) & 39.3 & 38.1 & 38.3 & 35.3 & 38.5 & 37.4 & 35.9 \\
\hline Oleic (C18:1) & 44.1 & 45.1 & 44.6 & 44.7 & 44.8 & 43.1 & 45.9 \\
\hline Linoleic (C18: 2) & 7.0 & 6.4 & 7.5 & 8.6 & 7.1 & 8.9 & 8.2 \\
\hline Linolenic (C18:3) & 0 & 0.4 & 0 & 0.4 & 0.4 & 0.4 & 0 \\
\hline Unknown & 2.0 & 2.1 & 2.0 & 2.3 & 2.1 & 1.9 & 1.7 \\
\hline C18:2/C16 & 0.9 & 0.8 & 1.0 & 1.0 & 0.9 & 1.1 & 1.0 \\
\hline
\end{tabular}


Extraction Time-Temperature Regime on Mango Kernel Lipids

\begin{tabular}{|c|c|c|c|c|c|c|c|}
\hline \multirow{2}{*}{ Fatty acid } & \multicolumn{7}{|c|}{ Extraction temperature $=60^{\circ} \mathrm{C}$, time $=2 \mathrm{hours}$} \\
\hline & D1 & D2 & D3 & D4 & D5 & D6 & D7 \\
\hline Palmitic (C16) & 8.1 & 8.3 & 7.0 & 8.6 & 8.8 & 7.9 & 8.0 \\
\hline Stearic (C18:0) & 36.0 & 36.8 & 36.9 & 36.0 & 33.8 & 39.2 & 37.4 \\
\hline Oleic (C18:1) & 44.6 & 44.1 & 45.6 & 44.8 & 44.6 & 43.1 & 42.5 \\
\hline Linoleic (C18: 2) & 8.5 & 8.1 & 7.8 & 8.4 & 10.8 & 9.8 & 8.7 \\
\hline Linolenic (C18:3) & 0.4 & 0.4 & 0.4 & 0 & 0 & 0 & 0 \\
\hline Unknown & 2.0 & 2.0 & 2.0 & 1.9 & 1.8 & 2.01 & 3.1 \\
\hline C18:2/C16 & 1.04 & 0.9 & 1.1 & 0.9 & 1.2 & 1.2 & 1.0 \\
\hline \multirow{2}{*}{ Fatty acid } & \multicolumn{7}{|c|}{ Extraction temperature $=60^{\circ} \mathrm{C}$, time $=4$ hours } \\
\hline & D1 & D2 & D3 & D4 & D5 & D6 & D7 \\
\hline Palmitic (C16) & 7.6 & 8.1 & 7.8 & 8.3 & 8.5 & 7.8 & 7.5 \\
\hline Stearic (C18:0) & 37.8 & 36.5 & 36.6 & 35.5 & 33.1 & 39.1 & 40.6 \\
\hline Oleic (C18:1) & 44 & 43.8 & 44.8 & 45 & 44.6 & 42.8 & 41.1 \\
\hline Linoleic (C18: 2) & 7.9 & 8.3 & 7.9 & 8.5 & 10.7 & 8.1 & 8.6 \\
\hline Linolenic (C18:3) & 0.3 & 0.5 & 0.4 & 0.4 & 0.4 & 0 & 0 \\
\hline Unknown & 2.0 & 2.5 & 2.3 & 2.0 & 2.5 & 2.0 & 1.9 \\
\hline C18:2/C16 & 1.0 & 1.0 & 1.0 & 1.0 & 1.2 & 1.0 & 1.1 \\
\hline
\end{tabular}

(D denotes drying temperature: $\mathrm{D} 1: 40^{\circ} \mathrm{C}, \mathrm{D2}: 60^{\circ} \mathrm{C}, \mathrm{D} 3: 80^{\circ} \mathrm{C}, \mathrm{D} 4: 105^{\circ} \mathrm{C}, \mathrm{D} 5: 180 \mathrm{~W}, \mathrm{D} 6: 360 \mathrm{~W}, \mathrm{D} 7: 540 \mathrm{~W}$ )

The values for qualitative parameters such as peroxide value, iodine value, saponification value and acid value are shown in Table 4. Peroxide value (PV) indicates the formation of hydroperoxides in the system which are the primary oxidation product of oils and unstable in nature. The effect on oil where seeds were dried at $540 \mathrm{~W}$ is significantly different than the rest of the conditions. The reason may be formation of free radicals at higher microwave power levels. This also concludes that mild power levels such as $180 \mathrm{~W}$ has less change in PV value when compared with hot air drying. Similar observations were noted in acid value where the sample dried at $540 \mathrm{~W}$ was found to show highest acid value among all, indicating the presence of freer carboxylic acid groups in lipid. The observation may be correlated with observed higher PV and similar findings have been reported for vegetable oils as discussed below. The values of iodine value and saponification value were found to be similar for all the conditions.

Table 4: Comparison between drying methods for their effect on oil quality

\begin{tabular}{|l|c|c|c|c|}
\hline Drying conditions & $\begin{array}{l}\text { Peroxide value } \\
\text { (mequiv/kg of oil) }\end{array}$ & $\begin{array}{l}\text { Iodine value } \\
\text { (mg/100gm of oil) }\end{array}$ & $\begin{array}{l}\text { Saponification value } \\
\text { (mg KOH/g) }\end{array}$ & $\begin{array}{l}\text { Acid value } \\
\text { (mg KOH/g) }\end{array}$ \\
\hline D2 & $0.1 \pm 0.02$ & $53.0 \pm 1.00$ & $189.3 \pm 1.0$ & $4.8 \pm 0.25$ \\
\hline D4 & $0.3 \pm 0.02$ & $57.5 \pm 0.50$ & $238.1 \pm 2.0$ & $5.2 \pm 0.47$ \\
\hline D5 & $0.3 \pm 0.01$ & $57.0 \pm 0.75$ & $231.0 \pm 0.9$ & $5.4 \pm 0.36$ \\
\hline D7 & $1.6 \pm 0.20$ & $64.3 \pm 1.05$ & $181.3 \pm 1.2$ & $6.6 \pm 0.25$ \\
\hline
\end{tabular}

(D denotes drying temperature: $\mathrm{D} 2: 60^{\circ} \mathrm{C}, \mathrm{D} 4: 105^{\circ} \mathrm{C}, \mathrm{D} 5: 180 \mathrm{~W}, \mathrm{D} 7: 540 \mathrm{~W}$ )

The ratio of $\mathrm{C} 18: 2$ (linoleic acid) to $\mathrm{C} 16$ (palmitic acid) denotes a standard for fat deterioration, linoleic acid being susceptible and palmitic acid being resistant to oxidation ${ }^{[16]}$. In this study it was found that the ratio observed matches well with the reference value. It did not differ significantly for conventionally dried kernels and microwave dried kernels. Linoleic acid though, was found to be less or absent in microwave dried kernels which is similar to the reported findings. Unsaturated bonds are prone to oxidative cleavage at higher temperature or accelerated reactions in the presence of microwave heating.

Previously microwaves were studied for pre treatment of oil seeds. A study on effect of microwave irradiation (lower power levels) on rapeseeds explains the increased yield of oil through cold press post microwave treatment. The qualitative parameters of the extracted oil were found to be similar to the control samples where no pre treatment was done ${ }^{[24]}$. Another study on effect of qualitative parameters post roasting of sunflower seeds showed significant decrease in oil content, increase in peroxide value, an increase in free fatty acid content and decrease in unsaturated fatty acid content (linoleic acid) when seeds were exposed to $500 \mathrm{~W}$ of power and roasting was done for 10 minutes $^{[25]}$. Exposures of vegetable oils to microwave heating were found to deteriorate the quality of lipids significantly as compared to hot air heating. An increase in the Trans isomeric form of unsaturated fatty acid was also reported ${ }^{[26-29]}$. Thus, the findings of our study match well with the phenomena discussed above. 


\section{Conclusion}

The two drying techniques; hot air drying and microwave drying were compared. The drying time using microwave (180W) was found to reduce significantly (by 34 folds) as compared to hot air drying $\left(60^{\circ} \mathrm{C}\right)$. The morphological studies suggested that higher temperature of drying and higher microwave power levels changes the structure of the kernel. The effect of heating was found to be prominent on starch granules and overlapping layers which may indicate protein de naturation due to heating. At higher temperature $\left(105^{\circ} \mathrm{C}\right.$ hot air drying/540 W microwave power) the globules were disrupted. The statistical analysis of lipid yields suggested that microwave drying and hot air drying both was comparable in terms of lipid yield. The extraction conditions under $40^{\circ} \mathrm{C} / 4 \mathrm{~h}$ or $60^{\circ} \mathrm{C} / 2 \mathrm{~h}$ were found to show less variation and thus $60^{\circ} \mathrm{C} / 2 \mathrm{~h}$ was chosen as optimum since it was close to boiling point of $\mathrm{n}$-hexane and time duration required was minimum. The quality of lipid was found to be consistent under all hot air drying temperatures while the degradation of oleic acid and linoleic acid were observed for samples dried at $540 \mathrm{~W}$ under the microwave. Though the ratio of unsaturated to saturated fat remains similar in both types of drying, the significant decrease in oleic acid content for highest microwave power level along with increased peroxide value and acid value indicated deterioration of lipid quality. Thus, from the above study it can be concluded that mango kernels can be dried best at $180 \mathrm{~W}$ microwave power level. Overall, on the basis of structural changes, lipid yield and lipid quality the optimized conditions were concluded as drying at $180 \mathrm{~W}$ microwave power, extraction at $60^{\circ} \mathrm{C}$ for $2 \mathrm{~h}$. Modifying the conventional extraction method in terms of time-temperature regime works well for mango kernels and lowering the extraction time to $2 \mathrm{~h}$ at higher temperatures did not affect the yield of lipid when dried with any method. Further studies can be done on effect of storage conditions on lipid quality. The residue left after lipid removal under optimized conditions may further be processed to recover starch and phenolics, thus, the complete process may be designed as a bio refinery.

\section{Acknowledgement}

We are grateful to the Ministry of Food Processing Industries (MOFPI) under Department of Science and Technology (DST) for providing funding through the external competitive grants program (Project ID: SERB/MOFPI/0036/2013).

\section{References}

1. http://www.apeda.gov.in/apedawebsite/six_head_product/PFV_OPF.htm

2. http://faostat.fao.org/site/339/default.aspx

3. Jahurul, M.H., Zaidul, I.S.M., Ghafoor, K., et al. Mango (Mangifera indica L.) by-products and their valuable components: A review. (2015) Food Chemistry 183:173-180.

4. Ajila, C.M., Aalami, M., Leelavathi, K., et al. Mango peel powder: A potential source of antioxidant and dietary fiber in macaroni preparations. (2010) Innovative Food Science and Emerging Technologies 11(1): 219-224.

5. Kittiphoom, S. Utilization of mango seed. (2012) International Food Research Journal 19(4): 1325-1335.

6. Sonwai, S., Kaphueakngam, P., Flood, A. Blending of mango kernel fat and palm oil mid-fraction to obtain cocoa butter equivalent. (2014) Journal of Food Science and Technology 51(10): 2357-2369.

7. Dhingra, S., Kapoor, A.C. Nutritive value of mango seed kernel. (1985) Journal of the Science of Food and Agriculture 36(8): 752-756.

8. Dhara, R., Bhattacharyya, D.K., Ghosh, M. Analysis of Sterol and Other Components Present in Unsaponifiable Matters of Mahua , Sal and Mango Kernel Oil. (2010) J Oleo Sci 59(4): 169-176.

9. Rukmini, C. Nutritional and Toxicological Evaluation of Mango Kernel Oil. (1984) Journal of American Oil Chemist's Society 61(4): 789-792.

10. Jahurul, M.H., Zaidul, I.S.M., Norulaini, N.N., et al. Supercritical carbon dioxide extraction and studies of mango seed kernel for cocoa butter analogy fats. (2013) CyTA J Food 12(1): 1-7.

11. Ratti, C., Belkacemi, K., Gutie, L. Food Chemistry Effects of drying method on the extraction yields and quality of oils from quebec sea buckthorn (Hippophae rhamnoides L.) seeds and pulp. (2008) Food Chemistry 106: 896-904.

12. Guldhe, A., Singh, B., Rawat, I., et al. Efficacy of drying and cell disruption techniques on lipid recovery from microalgae for biodiesel production. (2014) Fuel 128: 46-52.

13. Momeny, E., Rahmati, S., Ramli, N. Effect of Microwave Pretreatment on the Oil Yield of Mango Seeds for the Synthesis of a Cocoa Butter Substitute. (2012) Journal of Food Processing Technology 3(6): 164.

14. Adu, B., Otten, L. Microwave Heating and Mass Transfer Characteristics of White Beans. (1996) Journal of Agricultural Engineering Research 64(1): 71-78.

15. Prabhanjan, D.G., Ramaswamy, H.S., Raghavan, G.S.V. Microwave-assisted convective air drying of thin layer carrots. (1995) Journal of Food Engineering 25(2): 283-293.

16. Tan, C.P., Jinap, S., Yusoff, M.S., et al. Effects of microwave heating on changes in chemical and thermal properties of vegetable oils. (2001) Journal of the American Oil Chemists' Society 78(12): 1227-1232.

17. Zhang, M., Tang, J., Mujumdar, S., et al. Trends in microwave-related drying of fruits and vegetables. (2006) Trends in Food Science and Technology 17(10): 524-534.

18. Agarwal, R.K., Bosco, S.J.D. Optimization of viscozyme-L assisted extraction of coconut milk and virgin coconut oil. (2014) Asian Journal of Dairy and Food Research 33(4): 276-284. 
19. AOAC (1980) Official methods of analysis, 13th edition, Association of Official Analytical Chemists. Washington: DC.

20. Megazyme (2014) Total starch assay kit.

21. Li, C.Y., Li, W.H., Lee, B., et al. Morphological characterization of triticale starch granules during endosperm development and seed germination. (2011) Canadian Journal of Plant Science 91(1): 57-67.

22. Escher, F., Walther, P., Cunin, C. Structural changes of starch during cooking of Durum wheat Pasta. (1995) LWT Science Technology 28(3): 323-328.

23. Berdeaux, O., Fontagné, S., Sémon, E., et al. A detailed identification study on high-temperature degradation products of oleic and linoleic acid methyl esters by GC-MS and GC-FTIR. (2012) Chemistry and Physics of Lipids 165(3): 338-347.

24. Valentová, O., Novotná, Z., Svoboda, Z., et al. Influence of microwave treatment on the quality of rapeseed oil. (2002) Journal of the American Oil Chemists' Society 79(12): 1271-1272.

25. Anjum, F., Anwar, F., Jamil, A., et al. Microwave roasting effects on the physico-chemical composition and oxidative stability of sunflower seed oil. (2006) Journal of the American Oil Chemists' Society 83(9): 777-784.

26. Caponio, F., Pasqualone, A., Gomes, T. Changes in the fatty acid composition of vegetable oils in model doughs submitted to conventional or microwave heating. (2003) International Journal of Food Science and Technology 38(4): 481-486.

27. Wang, L., Weller, C.L. Recent advances in extraction of nutraceuticals from plants. (2006) Trends in Food Science \& Technology 17(6): 300-312.

28. Dhingra, S., Kapoor, A.C. Nutritive Value of Mango Seed Kernel. (2006) Science of Food and Agriculture 36(8): 752-756

29. FSSAI. Manual of methods analysis of oils and fats Ministry of Health and Family Welfare. (2012) Government of India: 24-40. 